\title{
Temporal trends in severe obesity prevalence in children and youth from primary care electronic medical records in Ontario: a repeated cross-sectional study
}

\author{
Sarah Carsley PhD, Eliza I. Pope BHSc, Laura N. Anderson PhD, Mark S. Tremblay PhD, \\ Karen Tu MD MSc, Catherine S. Birken MD MSc; for the Team to Address Bariatric Care in Canadian \\ Children
}

\section{Abstract}

Background: There are no current estimates of severe obesity in Canadian children. The objectives of this study were to determine the prevalence of severe obesity in children aged 18 years or less in Ontario and to determine temporal trends from 2004 to 2015.

Methods: This was a repeated cross-sectional study using height/length and weight of children aged 18 years or less from the Electronic Medical Record Administrative data Linked Database (EMRALD), a database of primary care electronic medical records in Ontario. We calculated body mass index (for age and sex) z-scores (zBMI). Two years of data (2014 and 2015) were used to determine the period prevalence of severe obesity. We used multivariable linear regression generalized estimating equations to estimate the association of calendar year and mean zBMI.

Results: In total, 55233 children were included. The prevalence of severe obesity (zBMl > 3) increased with increasing age: it was $0.9 \%(95 \%$ confidence interval $[\mathrm{Cl}] 0.7 \%$ to $1.0 \%)$ among children less than 5 years of age, $2.7 \%(95 \% \mathrm{Cl} 2.3 \%$ to $3.1 \%)$ among 5 - to 9-year-olds, $2.9 \%(95 \% \mathrm{Cl} 2.4 \%$ to $3.3 \%)$ among 10 - to 14 -year-olds and $3.7 \%(95 \% \mathrm{Cl} 3.1 \%$ to $4.3 \%)$ among those aged $15-18$. Boys aged 5-9 years had a significantly higher prevalence of severe obesity than their female counterparts $(3.5 \%$ [95\% $\mathrm{Cl} 2.9 \%$ to $4.2 \%$ ] v. $1.7 \%$ [95\% Cl $1.3 \%$ to $2.2 \%$ ]). From 2004 to 2015 , the mean zBMI decreased by $0.015(95 \% \mathrm{Cl}-0.018$ to -0.012$)$ units per year, with the overall prevalence of severe obesity in all ages highest in 2005 (3\%) and a decrease to $2 \%$ in 2015.

Interpretation: The prevalence of severe obesity among children and adolescents in Ontario is consistent with that in other developed countries with the exception of the United States. There is evidence of plateauing of estimates and a small decrease in zBMI over time. Further understanding of the impact of prevention efforts on these estimates is an important next step.

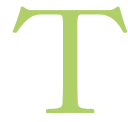

he prevalence of childhood obesity has increased around the world since 1980, with rates doubling in 73 countries. ${ }^{1}$ In $2015,107.7$ million children were classified as obese, for a worldwide prevalence of $5 \% .{ }^{1}$ Since 2000 , prevalence rates have started to plateau in some developed countries. ${ }^{2}$ However, national studies in the United States have shown conflicting trends, depending on the population studied. One study of low-income children aged 2-4 years enrolled in the Special Supplemental Nutrition Program for Women, Infants, and Children showed a decrease in severe obesity from 2004 to 2014. ${ }^{3}$ Another study of children aged 2-5 years using data from the National Health and Nutrition Examination Survey, a nationally representative sample, showed an increase in the prevalence of class 1 obesity ( $>95$ th percentile of body mass index [BMI] for age compared to the 2000 Centers for Dis- ease Control and Prevention growth charts) from 1999 to 2016, whereas the prevalence of both class 2 obesity (>120\% of the 95 th percentile) and class 3 obesity (> 140\% of the 95th percentile) remained stable. ${ }^{4}$ In Canada, using data from the Canadian Health Measures Survey, Rodd and Sharma $a^{5}$ found the prevalence of overweight or obesity among children aged 3-18 years to be declining, from $30.7 \%$ in 2004 to $27.0 \%$ in 2013 . It was not possible to

\section{Competing interests: None declared.}

This article has been peer reviewed.

Correspondence to: Catherine Birken, catherine.birken@ sickkids.ca CMAJ Open 2019. DOI:10.9778/cmajo.20180174 
estimate the proportion of children with severe obesity because of a lack of data from this nationally representative sample, with fewer than 500 children 3-5 years of age and no data for those less than 3 years. Therefore, less is known about severe obesity rates among Canadian children, as well as overweight and obesity in children less than 6 years.

Obesity and severe obesity in childhood have been associated with increased cardiovascular risk, ${ }^{6,7}$ obstructive sleep apnea, ${ }^{8}$ nonalcoholic fatty liver disease, ${ }^{9}$ impaired glucose tolerance ${ }^{10}$ and increased exposure to bullying. ${ }^{11}$ Furthermore, the severity of childhood obesity has been linked to the severity of these negative outcomes. ${ }^{6,12}$ Although Canadian national and provincial/territorial governments have prioritized childhood obesity prevention and management,${ }^{13}$ the degree of improvement in healthy weight in this country remains unclear. The absence of data on severe obesity in Canadian children constitutes a significant gap in our understanding of the topic. Continued population surveillance of prevalence and trends is essential to assess any impact of overarching public health policies, as well as evaluating investments in clinical programs and interventions. The primary objective of this study was to calculate the prevalence of severe obesity and to describe the trends in severe obesity in children and adolescents in Ontario from 2004 to 2015. The secondary objectives were to estimate the prevalence of all weight status categories and trends over time.

\section{Methods}

\section{Setting and study design}

This was a repeated cross-sectional study that included children aged 18 years or less over multiple years from Jan. 1, 2004, to Dec. 31, 2015. To determine the period prevalence of severe obesity (primary objective), we used 2 years of data (2014 and 2015). To describe weight status trends over time from 2004 to 2015 (secondary objective), we used all time periods.

\section{Study population}

Children were identified through the Electronic Medical Records Administrative data Linked Database (EMRALD), a database of family practices across Ontario. As of 2015, the database comprised 339 family physicians at 41 primary care practices. Children were included if the following criteria were met: physician had used an electronic medical record for a minimum of 2 years, patient was registered to an active EMRALD physician, patient had a valid identification num- ber to link with the administrative databases at ICES, and patient had a valid height/length and weight measurement to calculate the BMI z-score (zBMI). Patients had to be less than 19 years at the end of each year.

\section{Measurement}

We calculated zBMI by dividing weight (in kilograms) by height squared (in metres) and standardizing values by age and sex to the World Health Organization (WHO) Growth Standards and reference charts that are recommended for monitoring growth in Canada. ${ }^{14,15}$ We cleaned height and weight data using a standard set of data cleaning rules ${ }^{16}$ and excluded zBMI values outside -5 and 5 based on WHO recommendations for biologically implausible values. ${ }^{17}$ For the calculation of 2014-2015 prevalence, we used the most recent valid $z B M I$ measurement from a well-child visit. If no measurements were recorded during a well-child visit in the prevalence period, we used measurements obtained on the same date during any type of visit. We categorized weight status using WHO definitions (Table 1). Both the American Heart Association and the Centers for Disease Control and Prevention use definitions of severe obesity in children as young as 2 years; ${ }^{18,19}$ however, for children less than 5 years, the WHO defines the zBMI category of greater than 3 as obesity, not severe obesity. ${ }^{14}$ The WHO recommends an adjustment to the lambda-mu-sigma (LMS) method when examining data at the upper and lower extremes $(<-3$ and $>3$ ) because the tails of the Box-Cox normal distribution are affected by extreme data points. This restricted LMS method fixes the standard deviation between +2 and +3 to avoid making assumptions about the distribution of these extreme z-scores. ${ }^{20}$ For the purpose of this manuscript and for consistency between age groups, we applied the cutoff labels for children aged 5 years or more to all ages. ${ }^{21}$ Body mass index z-score cutoff values of 1,2 and 3 correspond approximately to the 85 th, 97 th and 99.9 th BMI percentiles, respectively. ${ }^{22}$

To control for changes in the distribution of potential confounding variables by year, we included several variables in the multivariable analyses. These were identified a priori based on previously established predictors of obesity and the available data sets at ICES and included age, sex, rural or urban residence, neighbourhood income quintile, the Ontario Marginalization Index, immigration status and ethnicity. ${ }^{23-25}$ We retrieved age and sex from the patient's electronic medical record. Rural or urban residence and income quintile were based on the patient's postal code and retrieved

\begin{tabular}{|llllll|}
\hline \multicolumn{5}{|c|}{ Table 1: World Health Organization definitions of weight status for children ${ }^{14}$} \\
\hline \multicolumn{5}{|c|}{ Body mass index z-score category; weight status } \\
\cline { 2 - 6 } Age, yr & $<-2$ & $\geq-2$ to $\leq 1$ & $>1$ to $\leq 2$ & $>2$ to $\leq 3$ & $>3$ \\
\hline$\geq 5$ & Underweight & Normal weight & Overweight & Obese & Severely obese \\
\hline$<5$ & Underweight & Normal weight & $\begin{array}{l}\text { At risk for } \\
\text { overweight }\end{array}$ & Overweight & Obese \\
\hline
\end{tabular}


through the Ontario Registered Persons Database, which is linked to 2006 Canadian census data. Similarly, the Ontario Marginalization Index is a census- and geographically based index that uses postal code as a proxy for individual-level sociodemographic characteristics; we used the summary score, which is a composite of 4 dimensions: material deprivation, ethnic concentration, dependency and residential instability. ${ }^{26}$ We determined immigration status of the child using the Immigration, Refugees and Citizenship Canada database. We categorized ethnicity as general population, Chinese or South Asian using a database that assigns ethnicity based on surname by means of a validated algorithm, used previously by others. ${ }^{27}$ Recent Canadian census data showed that the main non-European ethnicities reported were Chinese, East Indian and Filipino. ${ }^{28}$

\section{Statistical analysis}

We performed descriptive statistics on all variables to determine distributions and frequencies of baseline characteristics. To evaluate the potential generalizability of the findings to the entire province, we compared baseline characteristics of the children included in the prevalence period (2014-2015) to those of all Ontario children during the same period. We used the Registered Persons Database to identify children in Ontario aged 18 years or less as of Jan. 1, 2015, the halfway point in the time window. We excluded those with nonOntario postal codes and those not eligible for the Ontario Health Insurance Plan. To assess objective 1, we estimated prevalence and $95 \%$ confidence intervals (CIs) for zBMI categories by age group and by sex.

For objective 2, we performed a multivariable generalized estimating equation specified for linear regression to account for the influence of calendar time (year) on zBMI as a continuous outcome. The generalized estimating equation was used to adjust for the nonindependence of patients contributing BMI measurements to multiple years. The model also adjusted for potential confounding variables that may have changed the demographic characteristics of the patient population contributing data to each year, as previously described. We performed a second multivariable generalized estimating equation model specified for a multinomial regression using weight status as the dependent variable and 2004 as the referent year.

\section{Ethics approval}

This study was approved by the research ethics boards at the Sunnybrook Health Sciences Centre and The Hospital for Sick Children.

\section{Results}

\section{Study population}

We identified 67293 patients aged 18 years or less from 2004 to 2015 from the EMRALD database. Of the 67293 , $11508(17.1 \%)$ were ineligible owing to missing zBMI and $552(0.8 \%)$ were ineligible owing to implausible zBMI values. Overall, 31272 patients were included in the period prevalence estimate of severe obesity (2014-2015), and 55233 patients contributed 129859 zBMI measurements to the time trend analysis (2004-2015). Baseline sociodemographic characteristics of the EMRALD prevalence sample compared to the Ontario population are presented in Table 2. The EMRALD sample was generally younger, had a slightly higher proportion in the upper income quintiles, higher rural residence, a lower proportion of immigrants, and lower proportion of children of Chinese or South Asian ethnicity.

\section{Period prevalence of severe obesity}

In 2014-2015, the prevalence of severe obesity (zBMI > 3) among children and adolescents aged $5-18$ years was 3.0\% (95\% CI $2.7 \%$ to $3.2 \%$ ). The prevalence of each zBMI category is presented by age and sex in Table 3 . Overall, the prevalence of severe obesity increased with increasing age $(0.9 \%$ [ $95 \%$ CI $0.7 \%$ to $1.0 \%$ ] among children aged $\leq 4 \mathrm{yr}, 2.7 \%$ [95\% CI $2.3 \%$ to $3.1 \%$ ] among those aged $5-9 \mathrm{yr}, 2.9 \%$ [95\% CI $2.4 \%$ to $3.3 \%$ ] among those aged $10-14 \mathrm{yr}$ and $3.7 \%$ [95\% CI $3.1 \%$ to $4.3 \%$ ] among those aged $15-18 \mathrm{yr}$ ). There were differences in the prevalence of weight status by sex. The prevalence of severe obesity among boys aged $5-9$ years, $3.5 \%$ (95\% CI $2.9 \%$ to $4.2 \%$ ) was significantly higher than that among girls in this age group (1.7\% [95\% CI $1.3 \%$ to $2.2 \%]$ ).

\section{Trends over time}

From 2004 to 2015, after adjustment for age, sex, rural residence, neighbourhood income quintile, Ontario Marginalization Index, immigration status and ethnicity, there was a reduction in mean zBMI of 0.015 units per year (Table 4). Figure 1 shows the prevalence of overweight, obesity and severe obesity from 2004 to 2015 . Temporal trends in weight status prevalence by age group and sex are presented in Supplementary Figures S1 and S2, Appendix 1 (available at www.cmajopen.ca/content/7/2/E351/suppl/DC1). There was a noticeable decline in the prevalence of overweight and slight decreases in the prevalence of obesity and severe obesity. Children living in rural areas or low-income neighbourhoods had significantly higher zBMI values than those living in urban areas or higher-income neighbourhoods. These statistically significant associations were in the expected direction. Similarly, children of Chinese or South Asian ethnicity, and those who were immigrants had lower zBMI values compared to the general population. The association with the Ontario Marginalization Index was in the opposite direction to that expected: lower marginalization was associated with higher zBMI; however, as the upper CI was 0 , the clinical significance is questionable. The odds of being overweight, obese or severely obese decreased in almost all years after 2006 compared to 2004 (Figure 2). Compared to 2004, there was a significant decrease in the odds of being overweight in 2011-2015, lower odds of being obese in 2013-2014, and lower odds of being severely obese in 2012 and 2014. Results of a stratified multinomial regression by age group are presented in Supplementary Figure S3, Appendix 1. In 5-to 18-year-olds, despite a 


\begin{tabular}{|c|c|c|c|c|}
\hline \multirow[b]{2}{*}{ Characteristic } & \multicolumn{2}{|c|}{ No. $(\%)$ of children } & \multirow[b]{2}{*}{$\begin{array}{l}\text { Standardized } \\
\text { difference }\end{array}$} & \multirow[b]{2}{*}{$p$ value } \\
\hline & $\begin{array}{l}\text { EMRALD cohort } \\
\quad n=31272\end{array}$ & $\begin{array}{c}\text { Ontario } \\
n=2824213\end{array}$ & & \\
\hline \multicolumn{5}{|l|}{ Age, yr } \\
\hline$\leq 4$ & $15089(48.2)$ & $591178(20.9)$ & 0.60 & $<0.001$ \\
\hline $5-9$ & 6907 (22.1) & $774140(27.4)$ & 0.12 & \\
\hline $10-14$ & $5616(18.0)$ & 783517 (27.7) & 0.23 & \\
\hline $15-18$ & $3660(11.7)$ & 675378 (23.9) & 0.32 & \\
\hline \multicolumn{5}{|l|}{ Sex } \\
\hline Female & $15476(49.5)$ & $1375466(48.7)$ & 0.02 & 0.006 \\
\hline Male & $15796(50.5)$ & 1448747 (51.3) & 0.02 & \\
\hline \multicolumn{5}{|l|}{ Neighbourhood income quintile* } \\
\hline 1 (lowest) & 4255 (13.6) & $516726(18.3)$ & 0.13 & $<0.001$ \\
\hline 2 & $5979(19.1)$ & $507046(18.0)$ & 0.03 & \\
\hline 3 & $6818(21.8)$ & 562377 (19.9) & 0.05 & \\
\hline 4 & 7047 (22.5) & $639624(22.6)$ & 0.00 & \\
\hline 5 (highest) & $7018(22.4)$ & $585113(20.7)$ & 0.04 & \\
\hline Missing & $155(0.5)$ & $13327(0.5)$ & 0.00 & \\
\hline \multicolumn{5}{|l|}{ Rural $^{*}$} \\
\hline No & $26199(83.8)$ & 2522659 (89.3) & 0.16 & $<0.001$ \\
\hline Yes & $5073(16.2)$ & 300371 (10.6) & 0.16 & \\
\hline Missing & $0(0.0)$ & $1183(0.04)$ & 0.03 & \\
\hline \multicolumn{5}{|l|}{ Immigration status } \\
\hline Child is immigrant & $523(1.7)$ & $220095(7.8)$ & 0.29 & $<0.001$ \\
\hline Mother is immigrant & $3365(10.8)$ & $524378(18.6)$ & 0.22 & $<0.001$ \\
\hline \multicolumn{5}{|l|}{ Ethnicity* } \\
\hline General population & 29976 (95.9) & 2568987 (91.0) & 0.20 & $<0.001$ \\
\hline Chinese & $847(2.7)$ & $135869(4.8)$ & 0.11 & \\
\hline South Asian & $442(1.4)$ & 117957 (4.2) & 0.17 & \\
\hline Missing & $7(0.02)$ & $1400(0.05)$ & 0.01 & \\
\hline \multicolumn{5}{|l|}{ Chronic disease } \\
\hline Asthma & 3708 (11.9) & 547603 (19.4) & 0.21 & $<0.001$ \\
\hline Diabetes & $76(0.2)$ & $12644(0.4)$ & 0.03 & $<0.001$ \\
\hline $\begin{array}{l}\text { Complex chronic or congenital } \\
\text { condition }\end{array}$ & $1541(4.9)$ & $114769(4.1)$ & 0.04 & $<0.001$ \\
\hline
\end{tabular}

similar decrease in the odds of being overweight, obese or severely obese, the result was not significant.

\section{Interpretation}

The prevalence of severe obesity among children and adolescents aged 5-18 years was $3.0 \%$. The prevalence of severe obesity in boys in middle childhood (5-9 yr), 3.5\%, was sig- nificantly higher than that for girls in this age group (1.7\%). Rodd and Sharma ${ }^{5}$ reported that $16.3 \%$ of Canadian boys and $10.4 \%$ of Canadian girls were overweight or obese in 20122013 and that, after adjustment for potential confounders, girls were $19 \%$ less likely to be obese than boys. This sex difference was not seen in data on the reported prevalence of obesity and severe obesity from the National Health and Nutrition Examination Survey in the US. ${ }^{29}$ We found a small 
Table 3: Prevalence estimates of weight status by age and sex, 2014-2015

\begin{tabular}{|c|c|c|c|c|c|c|}
\hline \multirow{2}{*}{$\begin{array}{l}\text { Age group, } \\
\mathrm{yr}\end{array}$} & \multirow{2}{*}{$\begin{array}{l}\text { No. of } \\
\text { children }\end{array}$} & \multicolumn{5}{|c|}{ Body mass index z-score category; \% of children $(95 \% \mathrm{Cl})$} \\
\hline & & $<-2$ & $\geq-2$ to $\leq 1$ & $>1$ to $\leq 2$ & $>2$ to $\leq 3$ & $>3$ \\
\hline \multicolumn{7}{|l|}{ All children } \\
\hline$\leq 4$ & 15089 & $4.8(4.5$ to 5.1$)$ & 75.5 (74.8 to 76.1$)$ & $14.7(14.1$ to 15.2$)$ & 4.2 (3.9 to 4.5$)$ & $0.9(0.7$ to 1.0$)$ \\
\hline $5-9$ & 6907 & 2.3 (1.9 to 2.7$)$ & 72.7 (71.7 to 73.8$)$ & 15.1 (14.3 to 15.9$)$ & 7.0 (10.6 to 12.1$)$ & $2.7(2.3$ to 3.1$)$ \\
\hline $10-14$ & 5616 & $2.2(1.8$ to 2.6$)$ & $62.9(61.6$ to 64.2$)$ & 21.1 (20.0 to 22.2) & $10.8(10.0$ to 11.6$)$ & 2.9 (2.4 to 3.3$)$ \\
\hline $15-18$ & 3660 & 1.9 (1.4 to 2.3$)$ & $67.1(65.6$ to 68.6$)$ & $18.1(16.9$ to 19.4$)$ & $9.1(8.2$ to 10.1$)$ & 3.7 (3.1 to 4.3 ) \\
\hline Total & 31272 & 3.4 (3.2 to 3.6$)$ & 71.6 (71.1 to 72.1$)$ & 16.3 (15.9 to 16.7$)$ & 6.6 (6.3 to 6.8$)$ & 2.0 (1.8 to 2.1$)$ \\
\hline \multicolumn{7}{|l|}{ Boys } \\
\hline$\leq 4$ & 7683 & $5.0(4.5$ to 5.5$)$ & 73.7 (72.7 to 74.7$)$ & $15.3(14.5$ to 16.1$)$ & 4.8 (4.3 to 5.3$)$ & $1.2(0.9$ to 1.4$)$ \\
\hline $5-9$ & 3552 & 2.2 (1.8 to 2.8$)$ & 71.3 (69.7 to 72.7$)$ & $15.3(14.2$ to 16.5$)$ & 7.4 (6.5 to 8.3$)$ & 3.5 (2.9 to 4.2$)$ \\
\hline $10-14$ & 2824 & 2.4 (1.9 to 3.1$)$ & 61.5 (59.7 to 63.3$)$ & 20.5 (19.0 to 22.0 ) & $12.2(11.0$ to 13.4$)$ & 3.3 (2.7 to 4.0$)$ \\
\hline $15-18$ & 1737 & 2.8 (2.0 to 3.6 ) & 64.1 (61.8 to 66.4$)$ & 19.2 (17.4 to 21.1$)$ & 10.2 (8.9 to 11.8$)$ & 3.5 (2.7 to 4.0$)$ \\
\hline Total & 15796 & 3.7 (3.4 to 4.0$)$ & $69.9(69.2$ to 70.6$)$ & 16.6 (16.1 to 17.2$)$ & 7.3 (6.9 to 7.7$)$ & 2.3 (2.1 to 2.6 ) \\
\hline \multicolumn{7}{|l|}{ Girls } \\
\hline$\leq 4$ & 7406 & 4.5 (4.1 to 5.0$)$ & 77.3 (76.3 to 78.3$)$ & $14.0(13.2$ to 14.8$)$ & 3.5 (3.1 to 4.0$)$ & 0.6 (0.4 to 0.8$)$ \\
\hline $5-9$ & 3355 & 2.3 (1.8 to 2.9$)$ & 74.2 (72.7 to 75.7$)$ & $14.8(13.7$ to 16.1$)$ & 6.6 (5.8 to 7.5$)$ & 1.7 (1.3 to 2.2$)$ \\
\hline $10-14$ & 2792 & $2.0(1.5$ to 2.6$)$ & $64.4(62.6$ to 66.1$)$ & 21.8 (20.2 to 23.3$)$ & 9.4 (8.4 to 10.6$)$ & 2.4 (2.0 to 3.0$)$ \\
\hline $15-18$ & 1923 & $1.0(0.6$ to 1.6$)$ & 69.8 (67.7 to 71.8$)$ & $17.2(15.5$ to 18.9$)$ & 8.0 (6.9 to 9.4$)$ & 3.8 (3.0 to 4.8 ) \\
\hline Total & 15476 & 3.2 (2.9 to 3.4$)$ & 73.4 (72.7 to 74.1$)$ & $16.0(15.4$ to 16.6$)$ & 5.8 (5.5 to 6.2$)$ & $1.6(1.4$ to 1.8$)$ \\
\hline
\end{tabular}

decrease in mean zBMI of 0.015 units per year between 2004 and 2015. Prevalence estimates of overweight, obesity and severe obesity also decreased over this period, although this decline was not significant after adjustment for confounding variables. From 2011 to 2015, the prevalence of overweight, obesity and severe obesity was stable.

Before placing our findings in the context of international obesity prevalence estimates, it is important to note the differences in definitions of severe obesity in children. There are several different classifications for weight status, which vary by age, country and growth reference. The WHO definition of severe obesity begins at 5 years of age; there is no category of severe obesity for children less than this age. In the US, BMI for age for children and youth aged 2-20 years is compared with the 2000 Centers for Disease Control and Prevention growth charts. Class 2 obesity is defined as a BMI more than $120 \%$ of the 95 th percentile, or 35 or greater, whichever is lower, and class 3 obesity is defined as a BMI more than $140 \%$ of the 95 th percentile, or 40 or greater, whichever is lower. ${ }^{19}$ Other developed countries use the International Obesity Task Force definition for morbid obesity, which is equivalent to age- and sex-adjusted BMI at 18 years. ${ }^{30}$ Owing to the paucity of other provincial or Canadian estimates for severe obesity prevalence, the only comparative estimates are those from other developed countries. These comparisons should be made with caution because of the differences in definitions of severe obesity and the use of different growth reference charts. The highest estimate of severe obesity (class 2 and class 3 ) in children aged 2-17 years, about $8 \%$ in 1999-2014, comes from the US. ${ }^{31}$ National survey data from Australia indicated a prevalence of morbid obesity among 7 - to 15 -year-olds of $2.0 \%$ with the US definition $(1.8 \%$ with the International Obesity Task Force definition). ${ }^{32}$ Similarly, an estimate of $2.5 \%$ was reported from New Zealand for children aged 13-17 years in 2013 with the International Obesity Task Force definition. ${ }^{11}$ In the United Kingdom, the prevalence of severe obesity (defined as $\geq 99.87$ th percentile of the 1990 UK growth charts) was $1.5 \%$ for both girls and boys aged $4-5$ years, and $1.1 \%$ for girls and $1.2 \%$ for boys aged $10-11$ years. ${ }^{33}$ Taking into consideration the multiple limitations for comparison to these international estimates, our estimates of $3.0 \%$ for children aged $5-18$ years and $0.9 \%$ for those less than 5 years appear relatively consistent.

The decreasing trend in mean zBMI corroborates the most recent trends data from the Canadian Health Measures Survey, comparing the $2012 / 13$ cycle to the 2004/05 cycle. ${ }^{5,34}$ In the survey, the change in mean $\mathrm{zBMI}$ over the 10 -year period was -0.12 (95\% CI -0.2 to -0.05$)$ for children aged 3-17 years. We found a decrease of a slightly higher magnitude, 0.18 , if extrapolated over a 12 -year period. A review from 9 developed countries showed a mean rate of change in the prevalence of overweight and obesity of 0.01 and -0.01 , respectively, per year between 1995 and 2008 across all sex 


\begin{tabular}{|c|c|c|}
\hline Variable & Unadjusted estimate $(95 \% \mathrm{Cl})$ & Adjusted estimate $(95 \% \mathrm{Cl})^{*}$ \\
\hline Year & $-0.0146(-0.0177$ to -0.0115$)$ & $-0.0153(-0.0184$ to -0.0123$)$ \\
\hline Age & $0.049(0.0476$ to 0.0511$)$ & $0.0496(0.0478$ to 0.0514$)$ \\
\hline \multicolumn{3}{|l|}{ Income quintile } \\
\hline 1 & $0.0802(0.0473$ to 0.1131$)$ & $0.1427(0.105$ to 0.1804$)$ \\
\hline 2 & 0.0734 (0.0430 to 0.1039$)$ & $0.1162(0.0843$ to 0.1481$)$ \\
\hline 3 & 0.0627 (0.0338 to 0.0916$)$ & 0.0931 (0.0645 to 0.1217$)$ \\
\hline 4 & 0.0383 (0.0145 to 0.0099$)$ & $0.0644(0.0365$ to 0.0924$)$ \\
\hline 5 & Reference & Reference \\
\hline \multicolumn{3}{|l|}{ Sex } \\
\hline Female & $-0.0609(-0.0813$ to -0.0404$)$ & $-0.0703(-0.0902$ to -0.0503$)$ \\
\hline Male & Reference & Reference \\
\hline \multicolumn{3}{|l|}{ Residence } \\
\hline Rural & 0.1174 (0.0915 to 0.1434$)$ & 0.0911 (0.0656 to 0.1166$)$ \\
\hline Urban & Reference & Reference \\
\hline $\begin{array}{l}\text { Ontario Marginalization Score } \\
\text { (continuous) }\end{array}$ & $-0.0133(-0.0261$ to -0.0006$)$ & $-0.0178(-0.0328$ to -0.0028$)$ \\
\hline \multicolumn{3}{|l|}{ Ethnicity } \\
\hline General population & Reference & Reference \\
\hline Chinese & $-0.2745(-0.3393$ to -0.2097$)$ & $-0.2063(-0.2703$ to -0.1424$)$ \\
\hline South Asian & $-0.4649(-0.5604$ to -0.3694$)$ & $-0.3954(-0.4858$ to -0.3049$)$ \\
\hline $\begin{array}{l}\text { Household immigrant status } \\
\text { (reference }=\text { no) }\end{array}$ & $-0.0916(-0.1241$ to -0.0591$)$ & $-0.0227(-0.0552$ to 0.0098$)$ \\
\hline
\end{tabular}

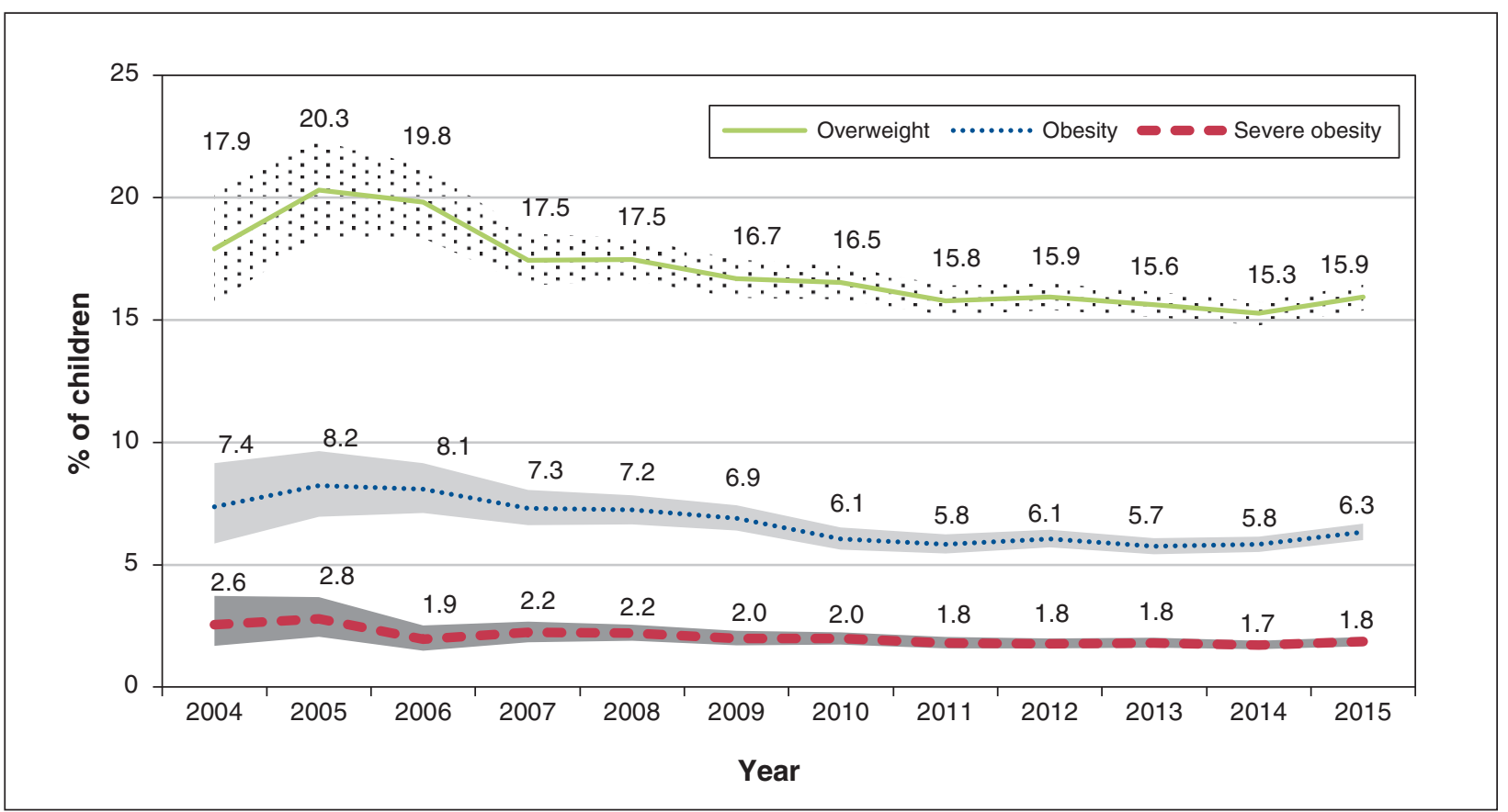

Figure 1: Prevalence of overweight, obesity and severe obesity among children aged 18 years or less from 2004 to 2015. Shaded areas represent $95 \%$ confidence intervals. 

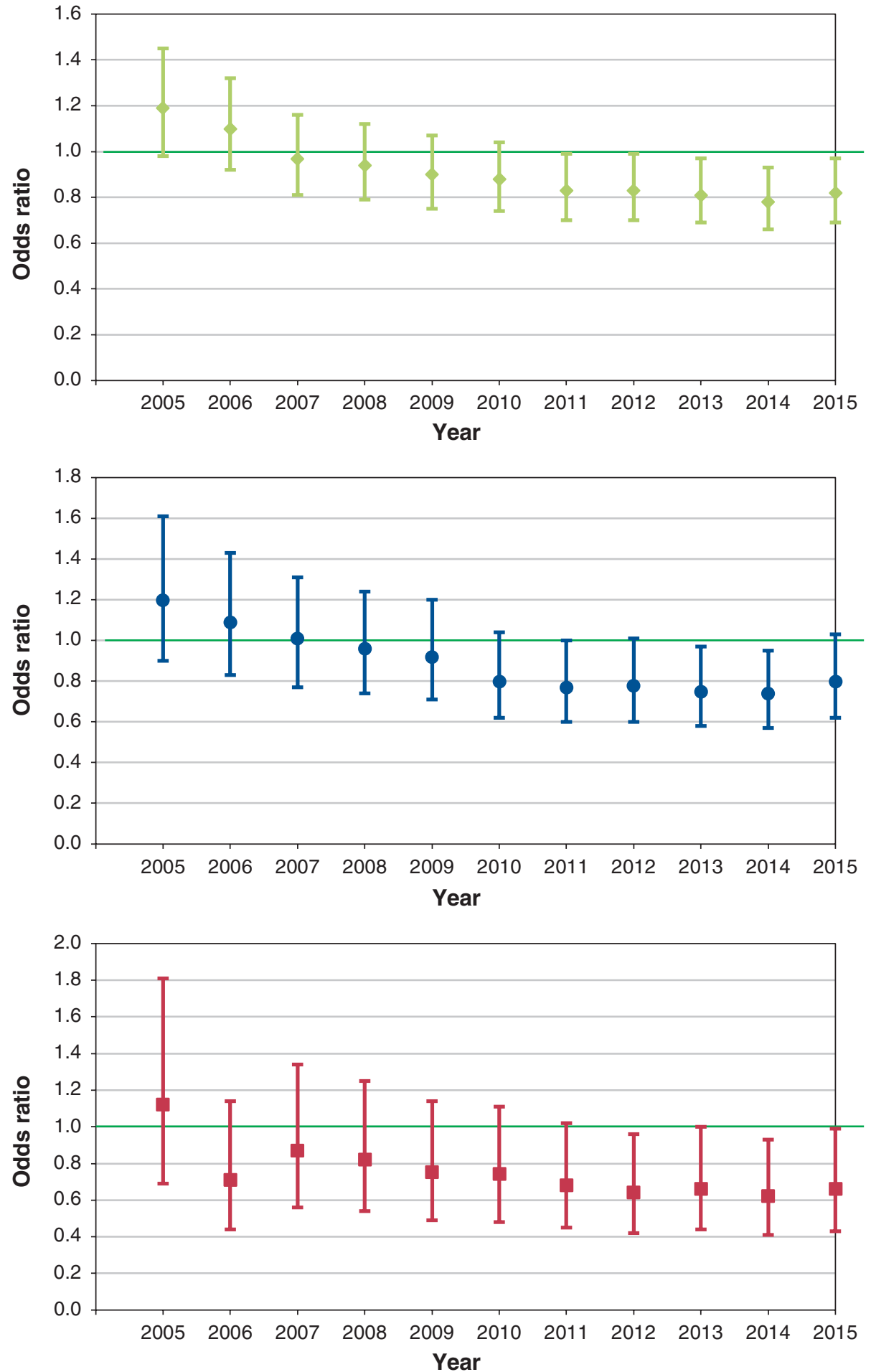

Figure 2: Multinomial regression model of the association between year (compared to 2004) and prevalence of overweight (top), obesity (middle) and severe obesity (bottom) among children aged 18 years or less. Error bars represent $95 \%$ confidence intervals. 
and age groups. ${ }^{35}$ Furthermore, in Australia, although there was an overall significant increase in the prevalence of morbid obesity from 1985 to $2012,{ }^{32}$ there was a plateau in the prevalence of obesity and morbid obesity from 2007 to 2014. ${ }^{36}$ Unlike in the US, where increasing trends in the proportion of 2- to 5-year-olds with higher levels of obesity (class 1, 2 or 3) were reported, ${ }^{4}$ our data showed no significant increase. Rather, there was a significant decrease in the prevalence of young children at risk for overweight, and stable estimates of obesity and severe obesity prevalence.

\section{Strengths and limitations}

Given the large sample and the longitudinal data in our study, we were able to provide estimates for all age groups and examine trends over multiple years. The use of routinely collected data from electronic medical records in primary care has many advantages ${ }^{37}$ including a relatively accessible source of valid measurement of BMI from health care providers. ${ }^{38}$ The completeness and accuracy of child height and weight measurements in EMRALD were examined previously and shown to be of high quality. ${ }^{39}$ Another analysis of weight status that used EMRALD data highlighted the strengths and limitations of this data source: ${ }^{40}$ a strength is the adequate sample size to investigate severe obesity prevalence, and a limitation is the lack of generalizability to all children in the Ontario and Canadian populations. Our EMRALD study population differed from the overall Ontario population on factors related to obesity ${ }^{41}$ and to routine use of primary care such as age, immigration status and neighbourhood income. Guttmann and colleagues ${ }^{42}$ reported that $12 \%$ of children in Ontario had no primary care physician visit billings over a 2 -year period, and children living in lower-income neighbourhoods were more likely to have no primary care billings than those in higher-income neighbourhoods. Our findings are generalizable to children and youth with a family physician who access primary health care in Ontario. Patients were excluded if there was no valid identification number and no valid height/length or weight measurement. In addition, 17\% of children did not have complete height and weight data, and it is unknown whether this would have under- or overestimated the results. It is also possible that children with severe obesity are not seen by primary care physicians routinely but, rather, by specialists or subspecialists. As such, the true prevalence of severe obesity may have been underestimated. The lack of data on chronic disease and obesity-related comorbidities is another limitation of this study and a future direction for research. We used a generalized estimating equation model to account for clustering of measurements within patients; however, we were unable to account for patients clustered by physician.

\section{Conclusion}

Our estimates of severe obesity prevalence among children and youth in Ontario are similar to estimates from other developed countries, excluding the US. Our results suggest a small decrease in overall mean zBMI, consistent with previous national Canadian data, and a plateauing of rates of over- weight, obesity and severe obesity over time. We were unable to attribute changes over time to any specific intervention or policy change. The prevalence of overweight, obesity and severe obesity was high, with about $25 \%-30 \%$ of children and youth above a normal weight and $2 \%-3 \%$ severely obese. In recent years, there has been increasing evidence that children as young as 2 years with extreme zBMI are at much higher risk for obesity-related comorbidities. A sustained clinical and public health focus on childhood obesity is still required to further reduce obesity rates. Continued monitoring and information about the prevalence and longitudinal trends of severe obesity will help to characterize the burden in childhood as well as inform potential therapeutic targets for this population.

\section{References}

1. Afshin A, Forouzanfar MH, Reitsma MB, et al. Health effects of overweight and obesity in 195 countries over 25 years. N Engl 7 Med 2017;377:13-27.

2. NCD Risk Factor Collaboration. Worldwide trends in body-mass index, underweight, overweight, and obesity from 1975 to 2016: a pooled analysis of 2416 population-based measurement studies in 128.9 million children, adolescents, and adults. Lancet 2017;390:2627-42.

3. Pan L, Freedman DS, Sharma AJ, et al. Trends in obesity among participants aged 2-4 years in the Special Supplemental Nutrition Program for Women, Infants, and Children - United States, 2000-2014. MMWR Morb Mortal Wkly Rep 2016;65:1256-60.

4. Skinner AC, Ravanbakht SN, Skelton JA, et al. Prevalence of obesity and severe obesity in US children, 1999-2016. Pediatrics 2018;141:pii: e20173459.

5. Rodd C, Sharma AK. Recent trends in the prevalence of overweight and obesity among Canadian children. CMA7 2016:188:E313-20.

6. Skinner AC, Perrin EM, Moss LA, et al. Cardiometabolic risks and severity of obesity in children and young adults. N Engl f Med 2015;373:1307-17.

7. Dalla Valle M, Laatikainen T, Kalliokoski T, et al. Childhood obesity in specialist care - searching for a healthy obese child. Ann Med 2015;47:639-54.

8. Tauman R, Gozal D. Obesity and obstructive sleep apnea in children. Paediatr Respir Rev 2006;7:247-59.

9. Sartorio A, Del Col A, Agosti F, et al. Predictors of non-alcoholic fatty liver disease in obese children. Eur 7 Clin Nutr 2007;61:877-83.

10. Sinha R, Fisch G, Teague B, et al. Prevalence of impaired glucose tolerance among children and adolescents with marked obesity. [published erratum in $N$ Engl F Med 2002;346:1756.] NEngl 7 Med 2002;346:802-10.

11. Farrant B, Utter J, Ameratunga S, et al. Prevalence of severe obesity among New Zealand adolescents and associations with health risk behaviors and emotional well-being. 7 Pediatr 2013;163:143-9.

12. Bell LM, Byrne S, Thompson A, et al. Increasing body mass index z-score is continuously associated with complications of overweight in children, even in the healthy weight range. 7 Clin Endocrinol Metab 2007;92:517-22.

13. Government of Canada's role in addressing childhood obesity. Ottawa: Public Health Agency of Canada; 2016. Available: www.canada.ca/en/public-health/ services/childhood-obesity/government-role-addressing-childhood-obesity.html (accessed 2019 Apr. 23).

14. WHO Multicentre Growth Reference Study Group. WHO Child Growth Standards based on length/height, weight and age. Acta Paediatrica Suppl 2006; 450:76-85.

15. de Onis M, Onyango AW, Borghi E, et al. Development of a WHO growth reference for school-aged children and adolescents. Bull World Health Organ 2007;85:660-7.

16. Smith N, Coleman KJ, Lawrence JM, et al. Body weight and height data in electronic medical records of children. I7PO 2010;5:237-42.

17. Physical status: the use and interpretation of anthropometry. Report of a WHO Expert Committee. World Health Organ Tech Rep Ser 1995;854:1-452.

18. Childhood obesity facts: prevalence of childhood obesity in the United States. Atlanta: Centers for Disease Control and Prevention; last reviewed 2018 Aug. 13. Available: www.cdc.gov/obesity/data/childhood.html (accessed 2019 Mar. 25).

19. Kelly AS, Barlow SE, Rao G, et al. Severe obesity in children and adolescents: identification, associated health risks, and treatment approaches: a scientific statement from the American Heart Association. Circulation 2013;128: $1689-712$.

20. WHO child growth standards: length/height-for-age, weight-for-age, weight-forlength, weight-for-height and body mass index-for-age: methods and development. Geneva: World Health Organization; 2006.

21. Satkunam M, Anderson LN, Carsley S, et al. Severe obesity in children 17 to 24 months of age: a cross-sectional study of TARGet Kids! and Better Outcomes Registry \& Network (BORN) Ontario. Can 7 Public Health 2018;109: 489-97. 
22. Dietitians of Canada; Canadian Paediatric Society; College of Family Physicians of Canada; Community Health Nurses of Canada; Secker D. Promoting optimal monitoring of child growth in Canada: using the new WHO growth charts. Can 7 Diet Pract Res 2010;71:e1-3.

23. Aris IM, Chen LW, Tint MT, et al. Body mass index trajectories in the first two years and subsequent childhood cardio-metabolic outcomes: a prospective multi-ethnic Asian cohort study. Sci Rep 2017;7:8424

24. Ogden CL, Fryar CD, Hales CM, et al. Differences in obesity prevalence by demographics and urbanization in US children and adolescents, 2013-2016. 7AMA 2018;319:2410-8.

25. Tu AW, Masse LC, Lear SA, et al. Body mass index trajectories from ages 1 to 20: results from two nationally representative Canadian longitudinal cohorts. Obesity (Silver Spring) 2015;23:1703-11.

26. Matheson FI, Dunn JR, Smith KL, et al. Development of the Canadian Marginalization Index: a new tool for the study of inequality. Can 7 Public Health 2012;103(8 Suppl 2):S12-6.

27. Shah BR, Chiu M, Amin S, et al. Surname lists to identify South Asian and Chinese ethnicity from secondary data in Ontario, Canada: a validation study. BMC Med Res Methodol 2010;10:42.

28. Vézina M, Maheux H. Ethnic and cultural origins of Canadians: portrait of a rich heritage. Ottawa: Statistics Canada; 2017. Cat no 98-200-X2016016.

29. Ogden CL, Carroll MD, Lawman HG, et al. Trends in obesity prevalence among children and adolescents in the United States, 1988-1994 through 2013-2014. 7AMA 2016;315:2292-9.

30. Bervoets L, Massa G. Defining morbid obesity in children based on BMI 40 at age 18 using the extended international (IOTF) cut-offs. Pediatr Obes 2014;9: e94-8.

31. Skinner AC, Perrin EM, Skelton JA. Prevalence of obesity and severe obesity in US children, 1999-2014. Obesity (Silver Spring) 2016;24:1116-23.

32. Garnett SP, Baur LA, Jones AM, et al. Trends in the prevalence of morbid and severe obesity in Australian children aged 7-15 years, 1985-2012. PLoS One 2016;11:e0154879.

33. Ells LJ, Hancock C, Copley VR, et al. Prevalence of severe childhood obesity in England: 2006-2013. Arch Dis Child 2015;100:631-6.

34. Rao DP, Kropac E, Do MT, et al. Childhood overweight and obesity trends in Canada. Health Promot Chronic Dis Prev Can 2016;36:194-8.

35. Olds T, Maher C, Zumin S, et al. Evidence that the prevalence of childhood overweight is plateauing: data from nine countries. IFPO 2011;6:342-60.

36. Xu J, Hardy LL, Guo CZ, et al. The trends and prevalence of obesity and morbid obesity among Australian school-aged children, 1985-2014. F Paediatr Child Health 2018;54:907-12.

37. Birtwhistle R, Williamson T. Primary care electronic medical records: a new data source for research in Canada. CMA7 2015;187:239-40.

38. Carsley S, Birken CS, Tu K, et al. Examining growth monitoring practices for children in primary care. Arch Dis Child 2018;103:406-7.

39. Carsley S, Birken CS, Parkin P, et al. Completeness and accuracy of anthropometric measurements in electronic medical records for children attending primary care. 7 Innov Health Inform 2018;25:963.
40. Birken CS, Tu K, Oud W, et al. Determining rates of overweight and obese status in children using electronic medical records: cross-sectional study. Can Fam Physician 2017;63:e114-22.

41. Rodd C, Sharma AK. Prevalence of overweight and obesity in Canadian children, 2004 to 2013: impact of socioeconomic determinants. Paediatr Child Health 2017;22:153-8.

42. Guttmann A, Lam K, Schultz SE, et al. Primary care for children. In: Jaakkimainen L, Upshur R, Klein-Geltink JE, et al., editors. Primary care in Ontario: ICES atlas. Toronto: Institute for Clinical Evaluative Sciences; 2006:35-51.

Affiliations: Department of Health Promotion, Chronic Disease and Injury Prevention (Carsley), Public Health Ontario; Faculty of Medicine (Pope), University of Toronto, Toronto, Ont.; Department of Health Research Methods, Evidence, and Impact (Anderson), McMaster University, Hamilton, Ont.; Healthy Active Living and Obesity Research (Tremblay), Children's Hospital of Eastern Ontario Research Institute, Ottawa, Ont.; Department of Family and Community Medicine (Tu), University of Toronto; Toronto Western Hospital Family Health Team (Tu), University Health Network; Peter Gilgan Centre for Research and Learning, Child Health Evaluative Sciences (Birken), the Hospital for Sick Children; Pediatric Outcomes Research Team, Division of Paediatric Medicine, The Hospital for Sick Children; Department of Pediatric Medicine (Birken), University of Toronto, Toronto, Ont.

Contributors: Sarah Carsley, Eliza Pope and Catherine Birken conceived and designed the study, analyzed the data and drafted the manuscript. Karen Tu, Laura Anderson and Mark Tremblay contributed to the study design. Catherine Birken, Karen Tu, Laura Anderson and Mark Tremblay contributed to data interpretation. All of the authors critically revised the manuscript for important intellectual content, approved the version to be published and agreed to be accountable for all aspects of the work.

Funding: This research was supported by a Team Grant in Bariatric Care (Team to Address Bariatric Care in Canadian Children [Team $\left.\mathrm{ABC}^{3}\right]$ ) from the Institute of Nutrition, Metabolism and Diabetes, Canadian Institutes of Health. Research partnership funding was provided generously by Alberta Health Services, Alberta Innovates - Health Solutions, the Canadian Obesity Network and the Ontario Ministry of Health and Long-Term Care. Karen Tu is supported by a Research Scholar Award from the Department of Family and Community Medicine, University of Toronto.

Supplemental information: For reviewer comments and the original submission of this manuscript, please see www.cmajopen.ca/content $/ 7 / 2$ / E351/suppl/DC1. 